\title{
A Question of Belonging: Reading Jean Arasanayagam through Nationalist Discourse
}

Elaine Y.L. Ho

The University of Hong Kong, Hong Kong

Harshana Rambukwella

The University of Hong Kong, Hong Kong

My eyes looking into yours tell me that I

Cannot belong...

Jean Arasanayagam

The assassination of Sri Lanka’s Foreign Minister Lakshman Kadirgamar ${ }^{1}$ last year was yet another stark reminder of the culture of violence bred by a decades-old ethnic conflict that has become the defining feature of politics in postcolonial Sri Lanka. The nation-state, that supposedly crowning achievement of European modernity, so often imagined as a space of liberal equality, seems a far cry from this turbulent postcolonial reality. It is easy for a Eurocentric worldview to dismiss this violence as either a manifestation of the primordial nature of the South Asian peoples or simply as a necessary step in the evolution of the Sri Lankan nation to full maturity. Yet as critics like Partha Chatterjee ${ }^{2}$ and Sankaran Krishna ${ }^{3}$ forcefully argue, the culture of ethnic intolerance, of which the assassination is a recent but by no means isolated event, is something written into the very fabric of the processes by which the colonial state was transformed into the 'imagined community' of the postcolonial nation-state. As Krishna ${ }^{4}$ demonstrates, the modular forms of European nationhood underwent radical changes in their dialectical encounter with the colony. Representative politics, which is supposed to guarantee the principle of equal citizenship based on the idea of 
an anonymous and homogenous civil society, shifted from representation to representativeness in the South Asian arena. Colonial practices of enumeration and census-taking, for instance, had generated a powerful numerical imagination among the colonized peoples, and had also aided in expanding their consciousness of belonging to a particular community and in thinking about it in terms of numbers. In the postcolonial world, this translates into a politics of numbers ${ }^{5}$ where the majority justifies its hegemony - as is the case with the Sinhala-Buddhist community in Sri Lanka - by arguing that it deserves the biggest share of national resources. The same numerical thinking also justifies a host of discriminatory practices that seek to ensure through state intervention that minorities are 'kept in place'. In Sri Lanka, the frequently rehearsed argument is that the Tamils were a pampered minority under colonial administration and that restricting their numbers in education, administration, professions, etc., is simply redressing the injustices of colonialism and restoring the nation to its true citizens, the Sinhalese. ${ }^{6}$

Yet where does the ideological content for seeing the Sinhala-Buddhists as the sole legitimate heirs of the Sri Lankan nation emerge? Is it simply a case of numerical imagination? The answer would have to be no. As Partha Chatterjee brilliantly demonstrated in the context of India, the real battle in anti-colonial nationalism takes place not in politics but in the realm of culture. ${ }^{7}$ This cultural domain is where nationalism sought to establish a zone of sovereignty unmarked by western influence, and as Chatterjee points out, it is here that nationalism realised some of its most powerful and 'authentic' historical achievements. However, it is also in the process of constructing this cultural domain that certain traditions and groups associated with them become marked as authentic whilst marginalizing and suppressing many other traditions and communities. If Benedict Anderson conceives the imagined community 
as a "deep horizontal comradeship", ${ }^{8}$ within the postcolonial nation of Sri Lanka, this comradeship becomes limited to an exclusive ethnic group while others are condemned to play the role of permanent guests on the peripheries of the nation. It is this question of cultural legitimacy that leads us to the poetry of Jean Arasanayagam. Placed as she is, at the crossroads of two minority identities - Burgher and Tamil - in the country, her work encapsulates a unique and complex response to the exclusionary nationalist rhetoric of postcolonial Sri Lanka.

As a writer of Dutch Burgher origin, ${ }^{9}$ married to a Tamil, the numerically largest and politically most assertive minority in the country, and living in the largely Sinhala-dominated southern part of the country, Arasanayagam's writing career shows her long-term engagement with the multiple heritages that inform her identity. If the dominant consciousness that emerges in her writing is "hybrid", as Neluka Silva terms it, ${ }^{10}$ it is an uneasy hybridity that is suffused with questions of what these heritages mean and of what sense she can make of them in the process of selfdefinition. One can see the discourses of exclusionary ethno-nationalism lurking in the shadows of her writing, and impinging upon the ways in which she writes her identity. It is very much under the sign of the postcolonial nation and its hegemonic discourses that Arasanayagam’s writing seeks its specific space. As Chatterjee points out in a rather Foucauldian formulation, the relationship of the dominant over the dominated is never total. Hegemony is never total in its reach: the dominated, though overdetermined by structures of suppression, always create a zone of autonomy. It is this zone of autonomy, and the contradictions that necessarily inhabit such a space, that we seek to explore in Arasanayagam's work. ${ }^{11}$

One of Arasanayagam’s earliest works, “Kindura”, the title poem of a 1973 collection, embodies the ambiguous potential of hybridity. The poem uses the half- 
human half-bird form depicted in the Buddhist legend Sanda Kinduru Jatakaya to suggest a potential for autonomy that might or might not gain full realisation:

Feathers slice off your waist,

Tail plumes splay the air,

Claws grasp earth,

Fingers touch flute,

Music twitters from those human lips,

Your imperturbable profile

Does not suggest

Discrepancy of disembodiment,

Yet your folded wings,

Unruffled feathers

Suggest an immobility

Of flight arrested,

And I see in my own

Submerged personality,

A strange, restless,

Ghost of Kindura. $^{12}$

The opening five lines focus on the kindura's flamboyant bird-like features and physique, poised on the brink of aggressive motion that resolves into a delicate, musical performance that is palpably human. Neither avian nor human, both avian and human - the kindura appears self-complete in its hybridity, its profile “imperturbable”. However, in the next few lines, this hybridity develops a more 
unsettling dimension - the kindura's 'unruffled feathers” that seem to signal outward calm are resignifed as immobility and "arrested flight". The doubleness of the kindura - its capacity for dynamic action and artistic performance hybridized with the intimation of potential unrealized - renders it problematic as the sign of Arasanayagam's self-identity as woman and poet. The concluding lines bring her mixed feelings to the fore in her vantage on her "submerged personality" as the ghost of kindura - both a shadow of the legendary creature and the site of its modern haunting. Will this "submerged personality" rise in flight, and will the shadow grow into bodily substance - these are questions the poem leaves unanswered.

It is interesting that in this early work, Arasanayagan draws inspiration from a Buddhist legend, and the consciousness of hybridity is cast within a mythological frame that draws upon what is popularly and traditionally seen as local - the Buddhist tradition. To fully appreciate the position Buddhism occupies in the majoritarian Sinhala imagination, one needs to look at a foundational myth that animates nationalist consciousness. The most enduring myth that sustains the Sinhalese claim to Sri Lanka as the land of the Sinhalese people is the belief that the Sinhalese are the chosen guardians of the Buddhist religion and that Sri Lanka is a special sanctuary for Buddhism. This intimate link between race, land, and nation that is justified in religious mythology has had a profound influence on postcolonial Sinhalese Buddhist nationalism. The legend of Prince Vijaya, the first mythic ruler of the land and the founder of the Sinhala race, arriving on the island somewhere in the fifth century BC, and the later arrival of Buddhism in the country signify the two most historically significant socio-cultural and political events for Sinhala Buddhists. Indeed, as Kingsley De Silva observes, the written chronicle of the country's history, the Mahavamsa, links Vijaya's arrival in Sri Lanka to a missive given by the Buddha on 
his deathbed to the supreme god Sakka which states that Vijaya - and by extension the Sinhala race - should be protected because Sri Lanka will be the future sanctuary of Buddhism. ${ }^{13}$ Thus, in referring to this powerful cultural imaginary, it is not only Arasanayagam's self-vantage as the kindura that is ambiguous. The adoption of the sign of the kindura argues an attempt to replace a hybrid consciousness in a majoritarian discourse that justifies itself in a singular and immemorial tradition promoted as authentically local. This attempt, which characterizes much of her work, is fraught with the ambivalence when a marginalized identity struggles to assert its autonomy from and yet also seeks articulation with dominant identity formations.

We can see a different manifestation of this ambivalence in Arasanayagam’s poems written a decade later, in the immediate aftermath of the 1983 anti-Tamil racial violence, of which she was an unwitting victim.${ }^{14}$ This difference needs to be explored in terms of both Arasanayagam's personal circumstance, and the shifting ethno-cultural contestations in postcolonial Sri Lanka. Due to her marriage to a Tamil, Arasanayagam comes face to face with nationalist violence that seeks to keep minorities like her 'in their place’:

It's all happened before and will happen again

And we the onlookers

But now I'm in it

It's happened to me

At last history has meaning. ${ }^{15}$

In this quotation from a poem pointedly titled “1958...'71....'77.....'81....'83”, the narrative voice deals with a history of repetitive violence. ${ }^{16}$ The dates in the title 
record a sporadic series of anti-Tamil riots in the country (except for ' 71 when a Maoist-style youth insurgency occurred in the south of the country). Having earlier perceived this violence from afar as an “onlooker”, the narrator now encounters it head on - she is now "in it" and "history has meaning". The numbers of the years that signpost the violent maturation of the postcolonial nation are now no longer abstract they are very much a part of the narrator's own history.

As Regi Siriwardena notes, Arasanayagam’s poems in the collection Apocalypse '83 from the immediate post-1983 period are spontaneous and powerful accounts of the futility of violence, but it is in her later poetry that she begins to dwell more intensely and deeply on the themes of identity and belonging that arise from the trauma of what happened to her and her family in $1983 .{ }^{17}$ Most critics of Arasanayagam’s work agree that 1983 was a significant event in her literary career, and that a marked note of urgency and political awareness emerges in her post-'83 writing. ${ }^{18}$ Yet, the specific directions that the writing takes, and the majoritarian meta-cultural discourses that shape this writing remain under-analysed. While Arasanayagam feels compelled to investigate her self-identity and position within a society she has inhabited from birth but now finds inimical, this investigation also generates a space of individual autonomy. It is, however, an ambivalent space that is neither totally within the nation as defined by majoritarian discourse, nor is it totally outside what could be loosely defined as a national imaginary. The sense of mythic calm the narrative voice of "Kindura" displays may no longer be visible; the hybrid consciousness has hardened and solidified into a minority consciousness aware of an ever-present majoritarian threat. Although the supposedly unmarked space of civil society that guarantees a notion of equal citizenship may have revealed its true exclusionary postcolonial reality, what emerges from the personal encounter with the 
violence of exclusionary ethno-nationalism is a resolute desire to seek a place, to belong.

A marked feature of Arasanayagam's post-'83 writing is an absence of the Buddhist mythological tradition that she draws upon in "Kindura". One could hazard an explanation by suggesting that post-' 83 , she sees the basic contradictions between a quietistic religious tradition and the violence that it could generate, or that she sees this tradition as territory from which she is excluded by virtue of her provenance and marriage. Whatever the reasons, there is far greater awareness and investigation of the two minoritized traditions that shape her self and cultural identity - Dutch Burgher and Tamil. It is in the investigation of these two traditions that her work enters into a much more complex dialogue with nationalism and its exclusionary discourses. Both traditions become valid sites in which to define subjectivity, and in that process, resist exclusions based on dichotomies of insider/outsider or indigenous/alien which are the hallmarks of nationalist cultural rhetoric. This is a writing of identity that redefines the Sri Lankan postcolonial space and marks it out as a site of multiple cultural heritages as opposed to the unitary logic of nationalism. But as pointed out earlier, the space of autonomy within which the dominated operate is itself a contradictory space - necessarily so due to the overdetermining influence of hegemonic discourses. It is from within the Sri Lankan nation and as an individual who desires to belong that Arasanayagam writes, but she is also acutely aware that in this national space, she is persistently marked as alien. The desire to belong co-exists with an equally urgent process of rewriting her own alien-ness, and to reinvent alienation as critical irony and poetic agency.

Turning first to the Burgher dimension of Arasanayagam's writing, one can see a proliferation of this in her work from 1985 onwards. The Burghers form one of 
the tiniest numerical minorities in the country, and enjoyed a position of wealth and high social status within colonial Sri Lanka. As Kumari Jayawardena notes, in colonial times, the Burgher community had a strong presence in the medical and legal sectors in the country and also considered themselves self-styled modernizers. ${ }^{19}$ But since independence in 1948, the Burghers have seen their numbers decline and their social and economic position threatened. ${ }^{20}$ It is, however, in the cultural sphere that they suffered the worst alienation. As Michael Roberts, a Sri Lankan social historian renowned for his work on Burghers notes, the term lansi used by the majority Sinhalese to denote Burghers identifies the marginalized space this community occupies in postcolonial Sri Lankan society:

... lansi could be (can be) employed relatively neutrally in a descriptive sense. But the context, the sequential order of face-to-face interaction and /or the intonation could render the term into a pejorative and polemical weapon which in effect cast the lansi as aliens in comparison with those deemed to be true sons of the soil, the bhumiputhrayo, ${ }^{21}$ the chosen Sinhala people. ${ }^{22}$

It is within such a discourse of linguistic and cultural peripheralisation that Arasanayagam investigates her Burgher ancestry. In the collection A Colonial Inheritance and Other Poems published in 1985, the narrative voice very selfconsciously seeks out the history of violence and exploitation that marks the arrival of the Dutch in Sri Lanka. The following lines from the poem, “Epics”, offer a small but revealing example: 
In the garden of the museum

A cannon rests. Within glass cases

Artefacts of time. Minted coins abraded

Silver larins, golden guilders, stuivers,

Ancient swords stained with rust

And blood. Firearms antique,

And in my face - a semblance. ${ }^{23}$

Colonial violence and economic exploitation are materialized in the form of a "canon" and bloodstained Dutch coins. The poetic persona is gazing at these artefacts through a glass case, and on the glass surface her reflection, palimpsestically superimposed upon the coins, reminds her of her own connection to this history - "And in my face a semblance”. As Benedict Anderson reminds us, museums play a central role in the national imagination. ${ }^{24}$ In a postcolonial context like Sri Lanka, they serve both as reminder of a 'glorious' pre-colonial past as well as in this case, the disruption and violence caused by colonialism. This colonial legacy is also another factor in the marginalisation of the Burghers. In the distorted logic of majoritarian nationalist consciousness, they are the miscegenated (non-pure) outcome of the colonial incursion which disrupted an indigenous ethno-cultural tradition. Though many of the Burghers are thoroughly assimilated, they continue to be seen as bearers of an oppressive colonial legacy. ${ }^{25}$

Arasanayagam's work does not shy away from colonialism’s exploitative history. But as it confronts this history as it is inscribed in her own body and indeed, her face, it also directs our attention to the accidental inevitability of her birth and the possibility of considering it as something miraculous - not an issue of a history of 
destruction but of creation. We see this possibility in lines from a poem entitled “Genealogies”:

Have I no shame, no guilt

That my inheritance came

With sword and gun...?

I am of their love

Not of their hate,

Perhaps of their lust,

The consummation

Of some brief bliss

That filled the cradle

Brimmed the grave,

I am their ultimate dream ${ }^{26}$

The "consummation of some brief bliss" brings to the fore the transience of the encounter which leads to her birth, perhaps hinting also at its accidental nature. But out of this accident, love, hope, and the capacity to dream are born. In the undertones of war and bloodshed, the narrator offers a different, positive vantage on her ancestry. A few lines later, she reiterates that her Burgher identity was not one acquired "by weapons that they used / But by some other miracle / Call it birth". ${ }^{27}$ The twin images of "miracle" and "cradle" combine to remind us of another birth, ancient in time and full of the promise of peace and resurrection - the birth of Christ. In her lived experience, questions of guilt and shame about her genealogy are intertwined with the 
possibility of her birth as a miraculous event promising a new and better human condition.

Arasanayagam’s work also seeks a broader identification with the suffering of women who were the victims, rather than agents, of a patriarchal colonialism. ${ }^{28}$ In "Maardenhuis - The House of the Virgins Amsterdam / Kalpitiya", from the collection Shooting the Floricans, Arasanayagam chronicles the suffering of Dutch orphan-virgins who were brought to Sri Lanka to be sexual partners or wives of 'second-class' Dutch colonisers. ${ }^{29}$ The tombstone of Johanna Van der Beck engraved with the poignant epitaph, “died in the childbed at fifteen, / Buried with her infant Pieter Jacobus”, standing forlorn in the Dutch Fort at Kalpitiya, inspires the narrator to imagine, recreate, and identify with the young Johanna in her tragic displacement from a life of privation in the virgin-house in Amsterdam - "Maardenhuis" - to the hardship of pregnancy and death in an alien tropical "Kalpitiya”. Enduring the rough passage on an unwholesome ship full of "the sweat and / Blood of men rotting with scurvy”, Johanna is transported as cargo, “destined” for use, "to bed with some humble / Foot soldier, halbedeer or pikeman.”30

The speaker re-enacts the humanity of a young woman who has been robbed of choice and agency, and whose history of suffering has long lain buried. It is not just Johanna's memory which is disinterred; she is resurrected in the poem as a subject of consciousness and feeling, alive in her sensations. The narrative of the poem is mimetic of this resurrection: it begins with a description of the tomb and its present surroundings, but then reaches back in time to bring Johanna back to life as it narrates her actual experience of the sea passage and arrival. Her suffering and eventual death after arrival are then represented vividly - she feels her "childbirth pangs" and "the poison chill creeping through” her limbs - but the narrative makes a further move 
back in time to recreate Johanna in the Maardenhuis before her journey:

You combed your hair by the fire in the

Maardenhuis, the nights were cold and

Wintersnow piled up on the cobbles...

Covering the square and the dreams of the

Virgins, restless before that unknown journey.

Already in your mind, maps began to form,

Stars from a midnight sky dotted the route,

In your dreams your body lurched against

The wood of the vessel, the flax spun linen

Tied up in a bundle to cushion your head,

Ruffled petticoats limp against your ankles. ${ }^{31}$

Displacing her role as a helpless virgin despoiled by the patriarchal colonial project, the poem shows Johanna as the subject of a "restless" imagination that can project - if only partially - the experience of the journey in bodily detail. Johanna is reborn, her subjectivity visible, her physical presence palpable. And like “Genealogies”, the poem attempts to transform the bleak summativeness of her death into a possible new beginning. Though Johanna dies in childbirth and her infant perished with her, the lines, "Gold grows dull in the grave / And silver tarnishes, only the earth is rich / As the white cerement of your skin / Shreds off”, 32 from the third stanza, which are repeated in the last stanza (without the last line), suggest that something is left behind - the image of the very skin enriching the soil. It could be provocatively argued that 
reappropriating the label of the miscegnated, the non-pure, what is intimated is the beginnings of a hybridized race in the whiteness of Johanna's skin mixing with the local soil.

Yet even as it reaches out to reinvent her Burgher heritage, Arasanayagam’s work also develops a critical distance from what this heritage has bestowed upon her. In a long poem entitled "Exiled Childhood" from the same collection, the narrative voice recalls with pleasure a protected and privileged childhood embodied in the care of "Mungo" the ayah and aunts who travel in a "great [ocean] liner" to a place the child can only imagine as a country spinning upon the surface of a globe - possibly England - and bring back fine gifts of "dresses with / tiers and frills of taffeta” in "bandboxes rustling with tissue", ${ }^{33}$ But the poetic persona disturbs this idyllic memory when she asks with self-irony: "who thought us anachronisms of that age? / We were part of an Empire’s glory”. This unsettling note, reinforced by a sudden crack of "thunder" that portends "stormy destinies", ${ }^{34}$ is repeated as the child reaches maturity, and in her debutante moment, compares herself to a pupa within a silk cocoon that is snatched before its moment of glorious emergence, and dropped in boiling water so that silk can be extracted:

I wore my dress sewn with a stroke of birdwing serrated stitches, honeycombed and bullioned at the waist, a spume of frothy pleats flowing over small sea rock, a clutched pupa bound within a chrysalis before it's snatched from mulberry leaf and dropped in searing water. ${ }^{35}$ 
On one level, the "searing water" could suggest entry into adulthood and the pressures it entails but there is also a note of unfulfilled promise. The beautifully decked out child-adult, like a butterfly or a bird, is set forth to spread her wings but like the image of the archetypal "Icarus" that occurs later in the poem, her moment of glory is short-lived. What drives this unsettling strain in the poem? Possible answers emerge in the later stanzas as the narrative voice recounts how her childhood world is bounded by social privilege and a westernized education, and kept apart from the broader local culture. The history books she read were written by "nineteenth century Victorians / a Cordiner or Davy” whose language she read "as if it were mine”, while all the time "wondering” whether the "pagan rites" and "devil-dancing” they spoke of were part of her own heritage. While the child watches a "Punch and Judy / show" in her house, children outside play on the street and "call[...] in tongues" she "did not know". ${ }^{36}$ In remembering this childhood world, the adult persona also realises that she has been conditioned by it; cut off from the outside world, whatever dim perception she has of it is distorted.

The ending of the poem captures the paradox of childhood remembrance as a process of self-realization and self-disavowal in the image of stilt-walkers in their awkward balancing act:

They gave us names settling uneasy on our limbs, silk stockings on the wooden legs of carnival men treading the streets teetering on dancing stilts.

Their glittering silver sequinned processional walks into the dark, the clacking echoes vanishing, 
the blazing torches ash. ${ }^{37}$

In their performance of identity in the public sphere, the Burghers, like the stiltwalkers, are artificially elevated by tradition, “teetering on dancing stilts.” Their discomfiture is accentuated by stilts clothed in ill-fitting "silk stockings" that "settle uneasily" on the limbs like the names "they” gave "us" - "they” here possibly referring to the colonisers or the colonial tradition in general which had a profound influence on the persona's life. They take part in the local carnival, but are they really an integral part of it? The final lines of the poem quoted above follow the stilt-walkers as they disappear into the dark, their departure marked not by community applause or fanfare but as a fade-out into disappearance from community itself. The self-identity in the poem is a troubled one for as it retrieves its own past in an act of self- and collective remembrance, it also perceives how this past is one of disarticulation from the indigenous life-world. The persona's - and by extension, the Burgher's - past distance from others is continuous with their present relegation by others to historical oblivion.

The persona's predicament is akin to that of the self-alienated colonised individual Fanon speaks of in Black Skin, White Masks - a self that has in some ways 'selved' the other and 'othered' the self. ${ }^{38}$ Alienated from her own past as she recognizes it as the source of her present alienation from others, the persona tries to recuperate some form of agency from her predicament. In the middle of the poem, she sees herself as a bird of "migrant breed" that in "overstaying / its summer, cohabiting with native kind" has "now grown / into this rare genus". ${ }^{39}$ It is no longer the mythical kindura but the bird, a living inhabitant of the local life-world, which now symbolizes Arasanayagam’s desire to find a place in Sri Lanka’s contemporary cultural ecology. The image articulates her desire to be recognized as migrant and 
foreign but also assimilated, through time, as a uniquely local life-form which, in its rarity, is worthy of preservation. This then is the zone of autonomy created by the desire of the dominated consciousness in its claims for recognition by majoritarian discourse.

It is at this point that we would like to turn to "another heritage" - the title of one of the sections in Shooting the Floricans - in Arasanayagam's work which, as Rajiva Wijesinha puts it, is “thrust” upon her by destiny - her connection to Tamil culture through marriage. ${ }^{40}$ As pointed out earlier, a heightened awareness and investigation of Tamil identity and culture emerge in Arasanayagam's post-'83 work following the racial violence she experienced as a consequence of being married to a Tamil. However, while marked as Tamil in the public sphere and having suffered for it, Arasanayagam’s work registers a complicated relationship of belonging and unbelonging with Tamil culture, one mediated, again through personal circumstance, by the less than friendly reception she receives from her husband's Tamil relatives. The Tamils are a far more dominant presence in Sri Lanka compared to the Burghers; next to the Sinhalese, they are the numerically largest and politically and culturally most assertive community in the country. As Darini Rajasingham-Senanayake points out, there is a "bi-polar" - Sinhala Buddhist versus Hindu Tamil - identity discourse in Sri Lanka today. ${ }^{41}$ Within this bi-polar configuration, other identities and communities like the Muslims and Burghers are pushed further aside. If Sinhala hegemony seeks power through essentialist master narratives, the Tamil response has been an equally essentialist counter-narrative that marks out the North and the East of the country as the "traditional homelands" 42 of the Tamil people, and to argue for a specifically Sri Lankan Tamil identity that has origins in antiquity and therefore valid claims to the Sri Lankan geo-political space. 
It is into a Tamil community very sensitised about its cultural and political claims that Arasanayagam enters as a Burgher, and she becomes a member of a community already othered by hegemonic nationalist discourses. One could safely suggest that in popular Tamil Hindu taxonomy, the Burghers would be as much alien as they are in the Sinhalese imagination. ${ }^{43}$ Within their essentialist selfconceptualisation, some Tamil groups would see themselves as bearers of an ancient and authentic local tradition while the Burghers are recent arrivals and the products of a history of colonial miscegenation. This exclusionary discourse in Tamil culture is focalised in Arasanayagam's work through the figure of the Tamil Hindu mother-inlaw in her encounter with the Burgher Christian daughter-in-law. Yet even as Arasanayagam's work ironises what is seen as insular in her mother-in-law's Vellala (high caste Hindu Tamil) culture, there is also desire to be a part of it. ${ }^{44}$ This duality is again underwritten by the contradictions of a dominated consciousness seeking a zone of autonomy: an outsider who seeks to be an insider but at the same time struggling against a position of subservience that the dominant culture allocates.

To explore some of the complexities of Arasanayagam's Tamil identity, we will turn to poems in her works, Reddened Water Flows Clear and Shooting the Floricans. ${ }^{45}$ In these poems, the daughter-in-law perceives the mother-in-law as a cultural custodian, surrounded by an intricate network of religio-cultural practices that define and provide meaning to the matriarch's life. Seeing the centrality of the matriarch in this culture and frustrated by the constant ostracism she suffers at her hands, the daughter-in-law seeks to enter the mother-in-law's space in the guise of a devotee, and in doing so, achieves a measure of recognition. However, it is important to note that Arasanayagam's portrayal of the matriarch and her cultural role has a distinct taste of the exotic to it. Unlike her writing on Burgher identity where there is 
a level of self-irony at the way she might be distorting what is local, the gaze here is of an outsider at times unaware of the ways in which her writing creates an exotic aura.

"Women Goddesses and Their Mythologies", 46 a long narrative poem, is emblematic of Arasanayagam's rendering of the daughter-in-law and mother-in-law relationship. The poem begins with an image of the ageing matriarch, her wealth and vitality diminished, which is contrasted with the past when she held sway. The narrator/daughter-in-law recounts with awe and a sense of vicarious pleasure her one and only entrance to the matriarch's shrine room - a site of fascination and desire for the narrator:

She] [a]llowed me once, but barely once to enter the sacred Room, gaze upon her shrine with saints and gurus And fold my hands in worship to those unknown gods

On whom she showered love, those goddesses of wealth And learning, those powerful deities whose towering lingams, Curling trunks, lotus and veenas inhabited the world Of her sacred legends and mythologies, where I, with Human limbs and eyes, whose sacrifice of blood fell On those empty stone altars where not one single god Would turn its eyes, belonged not to a single of her rituals, Yet I entered, treading uncertain and wavering with Naked sole, my feet, now unpolluted, washed and bathed In turmeric, first having shaken off the dust of many Journeys on roads and streets I trod ... ${ }^{47}$ 
The writing produces the mystical aura, an exotic strangeness that seems to inhabit this ritualised space; in this exoticization, we see not only the persona as novice arrival but also her attempt to relate to this other-space. Her every sensation is heightened in nervous apprehension of being in a sacred world she barely understands, and the privilege of being allowed in. She is cautious and tremulous; the necessary rites of entry have been undergone, and she is now purified, respectful and ready to be initiated. Her "uncertain” tread and "wavering” footsteps mark the entry of an outsider into what is a jealously guarded inner cultural domain. What is equally significant is that although this is the one and only time she has been able to step across, she has breached a symbolic barrier. The outsider achieves temporary insider status along with a sense of pleasure in her vicariousness gained through the ability to see, spy and report upon the mother-in-law's rituals.

Despite this brief entry into the mother-in-law's world, the strict cultural codes the matriarch observes continue to mediate the relationship between the two women and the mother-in-law looks “askance” upon the daughter-in-law as an "intruder” who fed on "unhallowed meats" and "mated / With those who were not always their kind." ${ }^{48}$ Here then is the essentialised cultural logic of the Hindu Tamil mother-in-law whose pure versus polluted taxonomy cannot accommodate the miscegenated Christian Burgher daughter-in-law - a micro-structure of the same cultural logic that operates as a meta-discourse of exclusion in the public sphere of the nation. In the movements between the pleasure of the initiate and the exposing and ironising of the matriarch’s parochialism, Arasanayagam constructs the daughter-in-law’s desire to belong but also her distancing as a more liberal and enlightened critic of a tenaciously preserved tradition. 
The poem's narrative trajectory proceeds to further encounters with the matriarch, and in the end, to a reversal of roles that shows the daughter-in-law confirmed in her position as insider. By the end of the poem, the daughter-in-law can celebrate her ability to procreate as a young mother in opposition to the matriarch grown "barren” with age. ${ }^{49}$ Neloufer de Mel has observed that this kind of depiction “invoke[s] patriarchal notions of womanhood as they discriminate against the infertile woman and widow”, ${ }^{50}$ While agreeing with de Mel's comment on how Arasanayagam's writing here reinforces patriarchal notions of womanhood, we can complicate this picture by suggesting that, as in her writing on Burgher identity, procreation stands for something larger than a mere position on which to celebrate a victory against the matriarch. Earlier in the poem, the old woman visits the daughterin-law, ostensibly "only to see / Whether [her] son is happy." ${ }^{51}$ But she also brings with her gold bracelets for the children, bracelets that are seen as "manacles of hierarchy" or "frail handcuffs" of "lineage” which the children will naturally outgrow, and the "snapped, bits and pieces" will be flung away in "choked drawers" 52 - long forgotten signifiers of the matriarch's ineffectual attempt to bring the children within her cultural domain. Yet the matriarch's actions here also signify acknowledgement of the children, and in that sense an unwitting acknowledgement of the mixing of her bloodline with that of the daughter-in-law's. We would posit that it is in this sense that the narrator sees the birth of the children as "my new/ Birth". ${ }^{53}$ These children can be seen as physical embodiments of a cross-cultural encounter that interrupts the exclusionary logic of the mother-in-law’s cultural consciousness, and simultaneously allow the daughter-in-law to construct for herself the insider position she yearns. Through these hybrid children, straddling two cultures, the daughter-in-law has 
continuity and a connection to the matriarch's culture but is also a source of cultural change.

Elsewhere in Arasanayagam's work, the identification with the mother-in-law sought for but only tentatively touched upon in "Women Goddesses and Mythologies” is made possible through what Sumathy Sivamohan terms a "womanist sensibility" - a sensibility that can identify with other women by forging connections through their shared roles as women. ${ }^{54}$ In “An Empty Temple”, a poem from Shooting the Floricans, the opening stanza sees the daughter-in-law washing out the matriarch's old room following her death, attempting to erase her memory. But the old woman's “smell” lingers in the room and the daughter-in-law recalls with some admiration the matriarch's zest for life in her "sensuous” yearning for the "ambrosial taste” of mangoes. ${ }^{55}$ As with Johanna, the empathy here is expressed in rich physical detail fusing the sensations of the two female bodies. In the last two stanzas, the identification between the two women returns to their first spiritual connection in the shrine-room - but with a distinct difference. In these stanzas, the matriarch's room is transformed into a "temple” in the narrator's imagination, and she is the devotee, serving the goddess/matriarch. There is a further twist: in a role-reversal in the last line, the daughter-in-law becomes the goddess when the matriarch addresses her as "Iswari” (Sivamohan observes that this is one of the many names of the goddess Shakti): ${ }^{56}$

Her room is like an empty temple now and There's no one to hold incense or burn camphor To the ghost of a forgotten image. 
Once, and now I wonder at it,

When I bore, in my two hands my daily offerings

To her as if I were the last to visit the sanctum,

It was she who called me

"Iswari.",57

As Sivamohan observes, the mythologizing of the relationship gives meaning to the daughter-in-law’s life who, “coming down in the line of women serving women”, lives out the myth of the goddess. ${ }^{58}$ The daughter-in-law who earlier attempts to erase the old woman's memories now makes room for both in the “temple”, and in a direct line of descent, steps into the goddess' role in her position as the latest matriarch, a role and position which the mother-in-law is shown to recognise. The relationship thus breaks away from the two women's socialised identities as Tamil Hindu and Burgher Christian, and finds common ground within the tradition of women who serve other women as well as within the mythologized sphere of goddess and devotee. In both poems, "Women, Goddesses and Their Mythologies” and "An Empty Temple”, it is the act of writing that enables the narrative consciousness to both participate in as well as resist her mother-in-law's culture. This imaginative power of the artist as poet is nowhere better captured in Arasanayagam's writing than in a short poem titled "Poet”. Here, the poet conceives of herself as a common woman, oppressed by the institutions of society, and to all appearances a victim. But within her lies a power for creation known only to herself, an implied subversive potential:

Creeps into a misthole to vanish 
But doesn't.

Walks through the hot sunshine with

Dust between toes,

Is pressed back by huge, green military trucks

Is almost crushed

I watch her

She takes the hem of her garment and

Wipes the sweat off her brow

The thin cotton is damp and stained.

She tells herself,

"I am common

Anonymous like all others

Here.

No one knows that I have magic

In my brain., 59

The poet is on indigenous ground, no different from other women "common” and "anonymous", adapted to the discomforts and harassments of an everyday journey through the "dusty" roads. But this locatedness and identification is informed also by a proud sense of her difference: she has "magic" in her brain. It is this "magic" of her imaginative power as a writer that allows her to inform the world of her and her fellow beings' suffering, and also to construct imaginative spaces that can exceed those allocated to them by society. It is in this writerly space that Arasanayagam 
engages in her project of self-fashioning - a self that is Sri Lankan in a broad and inclusive sense.

Writing within a postcolonial Sri Lanka where nationalist master narratives have created a cultural imagination entrenched in dichotomies of insider/outsider, indigenous/alien and pure/polluted, Arasanayagam's writing seeks a space that would locate her within the nation-state as an author of her own self-determination. The encounter with these meta-narratives of exclusion produces in her writing both a desire to belong but also a simultaneous desire for distance. If the national, the local or the indigenous is a space where what is considered marginal can only occupy a position of subservience, the marginal seeks to redefine that space and thereby stake a claim with dignity. Some would describe this as the generation of a "third space" in Homi Bhabha’s terms. ${ }^{60}$ But rather than a cosmopolitan conception of hybridity embodied in a subject who can move freely within a borderless world available to those plugged in to the circuits of global capitalism - the consciousness in Arasanayagam is one still heavily invested in the idea of Sri Lanka, an investment reflected in her choice to live and write within the country. She writes from within the nation and as one who wishes to belong to it. To invoke Stuart Hall, Arasanayagam's writing reveals a process of "becoming" 61 and in that sense destabilises the unitary logic of essentialised conceptions of identity, but at the same time is acutely conscious of the value of cultural identity. The desire and the longing for a place to locate the self is writ large in her work. She remains very much a part of the postcolonial Sri Lankan nation - but a nation that is redefined to reflect a multiplicity lacking in its exclusive nationalist rhetoric. 


\title{
The authors wish to acknowledge Sumathy Sivamohan, University of Peradeniya, Sri
}

\author{
Lanka, for her helpful comments on an earlier draft of this paper.
}

\section{Notes}

\begin{abstract}
${ }^{1}$ Sri Lankan Foreign Minister Lakshman Kadirgamar was assassinated in the late evening of $12^{\text {th }}$ August 2005 at his private residence by a suspected Tamil Tiger sniper. Kadirgamar's assassination came in the midst of a faltering truce between the Sri Lankan State and the separatist Tamil Tigers (the Liberation Tigers of Tamil Elam or LTTE which is fighting for an autonomous state in the North and East of the county) and has added to fears that the long-awaited resumption of peace talks between the Tigers and the State would not materialise.
\end{abstract}

${ }^{2}$ Partha Chatterjee, The Nation and its Fragments: Colonial and Postcolonial Histories, Princeton, N.J.: Princeton University Press, 1993.

${ }^{3}$ Sankaran Krishna, Postcolonial Insecurities: India, Sri Lanka, and the Question of Nationhood, New Delhi: Oxford University Press, 1999.

${ }^{4}$ ibid

5 Arjun Appadurai, “Number in the Colonial Imagination”, In Orientalism and the Postcolonial Predicament, edited by Carol Breckenridge and Peter Van der Veer, Philadelphia: University of Pennsylvania Press, 1993, pp. 314-339.

${ }^{6}$ An extended analysis of this numerical imagination and how it has impacted Sri Lankan postcolonial politics can be found in the chapter entitled "Producing Sri Lanka from Ceylon: J.R. Jayawardene and Sinhala Identity”, in Postcolonial Insecurities, pp. 31-58.

${ }^{7}$ Chatterjee argues in The Nation and its Fragments, that while the West had proven beyond doubt its superiority in the material/public sphere and that Indian nationalism aggressively sought this modernity in the public realm, the spiritual or private sphere was marked out as a domain that was different in all aspects to the West and was considered a space unpolluted by colonial contact and therefore needed to be jealously guarded. This is the space that allows Indian nationalism to claim uniqueness. Thus from its outset anticolonial nationalism is marked by a contradictory impulse that seeks modernity in the public realm while resisting it in the private or spiritual realm.

${ }^{8}$ Benedict Anderson, Imagined Communities: Reflections on the Origin and Spread of Nationalism, London: Verso, 1991, p. 7.

${ }^{9}$ The Burghers in Sri Lanka are the result of intermingling between the Portuguese, Dutch, English, Sinhalese and Tamils. They are usually identifiable by their names and sometimes-fairer skin colour. They are also mostly Catholic or Protestant Christian in religion.

${ }^{10}$ Neluka, Silva, 2002, "Situating the Hybrid 'Other' in an Era of Conflict: Representations of the Burgher in Contemporary Writings in English”, in The Hybrid Island: Culture Crossings and the Invention of Identity in Sri Lanka, edited by Neluka Silva, London: Zed Books, 2002, pp. 104-126.

${ }^{11}$ The Nation and its Fragments, pp. 158-163. Chatterjee's formulation of the idea of an autonomous zone is in relation to the peasant insurgencies of colonial India, and the Subaltern Studies Group's attempts to narrate this history by placing the peasants as subjects and agents of their own history, rather than as a community always acted upon by outside forces. Chatterjee argues that neither colonial administration nor elite Indian nationalism could totally extend their respective hegemonies over the Indian peasantry. A domain of autonomy where the peasants were their own self-authors always existed. 
12 Jean Arasanayagam, 1973, Kindura, Kandy, Sri Lanka: Privately Published, p. 2.

13 A detailed account of this foundational myth can be found in Kingsley M. De Silva, A History of Sri Lanka, Chennai: Oxford University Press, 1981, pp. 3-4.

${ }^{14}$ On July 23, 1983, there was a massive wave of violence throughout the country against the Tamil minority on an unprecedented scale. Sparked off by the killing of 13 Sri Lankan army soldiers by Tamil rebel forces in the North of the country, these riots claimed almost 2000 Tamil lives, and displaced thousands by rendering them homeless and destitute. There was also large-scale property damage with Tamil households and businesses targeted by organised Sinhalese gangs. It is widely believed that the state was very late in responding to the situation and thereby deepened the mistrust of the Tamil minority about the Sri Lankan state's capability, and indeed, readiness to safeguard their rights. Arasanayagam's home was attacked on account of her husband being Tamil and the family had to seek refuge with neighbours and later in government refugee camps.

${ }^{15}$ Jean Arasanayagam, Apocalypse '83, Colombo, Sri Lanka: International Centre for Ethnic Studies, 2003, p. 26.

${ }^{16}$ The collection Apocalypse '83 was originally published in 1984 and re-published in 2003.

${ }^{17}$ Regi Siriwardena, “Jean Arasanayagam: In Search of Identity”, in Apocalypse '83, by Jean Arasanayagam, Colombo, Sri Lanka: International Centre for Ethnic Studies, 2003, pp. 3-8.

${ }^{18}$ Rajiva Wijesinha, Introduction to Shooting the Floricans, by Jean Arasanayagam, Kandy, Sri Lanka: Samjna, 1993, pp. v-viii; Ashley Halpe, "Excerpt from Some Aspects of Recent Sri Lankan Literature in English”, in Apocalypse '83, by Jean Arasanayagam, Colombo, Sri Lanka: International Centre for Ethnic Studies, 2003, pp. 1-2; “Jean Arasanayagam: In Search of Identity”.

${ }^{19}$ Kumari, Jayawardena, Nobodies to Somebodies: The Rise of the Colonial Bourgeoisie in Sri Lanka, Colombo: Social Scientist’s Association and Sanjiva Books, 2003, pp. 231-248.

${ }^{20}$ A major factor in the Burgher decline was the national language policy of 1956 which made Sinhala the state language thereby sealing off the advantage Burghers had through their English education. Large numbers of Burghers migrated to Australia and Britain in the 1960s following this policy shift. 1956 also marks a turning point in the Tamil community's mounting disenchantment with Sinhala nationalism. Due to strong Tamil protests, the language policy was amended later to give Tamil special administrative status in the Tamil and Muslim (the language of Muslims in Sri Lanka is also Tamil) dominated North and East of the country. However, English, the language of the Burghers, did not receive such recognition and the Burgher community was numerically too small to effectively pressurise the state.

${ }^{21}$ Bhumiputhrayo literally translates as 'sons of the soil' (bhumi meaning soil or land and puthrayo meaning sons).

${ }^{22}$ Michael Roberts, Transformation of the Burghers of Sri Lanka: From "Ceylonese" to Outcaste, 1850s - 1970s, Paper presented at the International Conference on Indian Ocean Studies, Perth W.A., Australia, 5-12 December 1984, p. 3.

23 Jean Arasanayagam, A Colonial Inheritance and Other Poems, Kandy, Sri Lanka: Privately Published, 1985, p. 5.

${ }^{24}$ Imagined Communities, pp. 178-185.

${ }^{25}$ A sense of Burgher-imperialist collusion further strengthened in the majority's mind by the privileged and high-visibility positions some Burghers held within the colonial economy and administrative structure. In People Inbetween (1989), the most detailed sociological study of Burgher identity in Sri Lanka to date, Michael Roberts et al. elucidate the complex and contradictory discourse 
through which Burghers are marginalized. On the one hand they are seen as impure and polluted but at the same time they are also seen as privileged because of their access to the English language and the vanguard positions some sections of the Burgher community held in colonial times.

Michael, Roberts; Ismeth Raheem; Percy Colin-Thomé, People Inbetween: The Burghers and the Middle Class in the Transformations within Sri Lanka, 1790s - 1960s, Volume I, Ratmalana, Sri Lanka: Sarvodaya Vishva Lekha, 1989.

\section{${ }^{26}$ A Colonial Inheritance, p. 7.}

27 ibid

${ }^{28}$ Sumathy Sivamohan aptly terms this a "womanist sensibility” that extends throughout Arasanayagam's writing allowing her to reach out to women from different communities and walks of life. A detailed discussion of this idea can be found in:

Sumathy Sivamohan, "Becoming Women: Traveling Gender and Identity Politics in Four Women's Texts”, Indian Women's Writing: Some Feminist Issues, edited by R.K. Dhawan and A. Monti, New Delhi: Prestige, 2002, pp. 247-293.

${ }^{29}$ Jean Arasanayagam, Shooting the Floricans, Kandy, Sri Lanka: Samjna, 1993, pp. 1-4.

30 ibid, pp. 2-3.

31 ibid, p. 3.

32 ibid, p. 1.

33 ibid, pp. 9-10.

${ }^{34}$ ibid, p. 10.

${ }^{35}$ ibid, p. 11.

${ }^{36}$ ibid, p. 12.

${ }^{37}$ ibid, p. 14.

${ }^{38}$ Frantz Fanon, “The Fact of Blackness”, Black Skin, White Masks, New York: Grove Press, 1967, pp. 109-140.

${ }^{39}$ Shooting the Floricans, p. 13.

${ }^{40}$ Rajiva, Wijesinha, “Introduction”, Shooting the Floricans, pp. v-viii.

${ }^{41}$ Darini, Rajasingham-Senanayake, "Democracy and the Problem of Representation: The Making of Bi-polar Ethnic Identity in Post/Colonial Sri Lanka”, In Ethnic Futures: The State and Identity Politics in Asia, edited by Joanna Pfaff-Czarnecka, Darini Rajasingham-Senanayake, Ashis Nandy and Edmund Terrence Gomez, New Delhi: Sage Publications, 1999, pp. 99-134.

${ }^{42}$ Dagmar, Hellman-Rajanayagam, “The Politics of the Tamil Past”, In Sri Lanka: History and the Roots of Conflict, edited by Jonathan Spencer, London: Routledge, 1990.

${ }^{43}$ People Inbetween.

${ }^{44}$ Arasanayagam's writing on Tamil identity and culture are far more personalised than her investigation of Burgher heritage. There is a strong biographical element in her writing on Tamil identity with direct references to her in-laws by name.

${ }^{45}$ Jean Arasanayagam, Reddened Water Flows Clear, London: Forest Books, 1991.; Shooting the 
Floricans.

${ }^{46}$ Reddened Water, pp. 29-33.

${ }^{47}$ ibid, pp. 29-30.

${ }^{48}$ ibid, pp. 30-31.

${ }^{49}$ ibid, p. 32.

${ }^{50}$ de Mel, Neloufer, "Excerpt from Static Signifiers: Metaphors of Woman in Contemporary Sri Lankan War Poetry”, in Shooting the Floricans, p. xiv.

${ }^{51}$ Reddened Water, p. 31.

52 ibid, pp. 31-32.

${ }^{53}$ ibid, p. 32.

54 “Becoming Women”.

${ }^{55}$ Shooting the Floricans, pp. 45.

56 “Becoming Women”, p. 254

${ }^{57}$ ibid, p. 46.

58 “Becoming Women”, p. 254.

${ }^{59}$ Shooting the Floricans, p. 126.

${ }^{60}$ Homi, K. Bhabha, “The Third Space: Interview with Homi K. Bhabha”, In Identity: Community, Culture, Difference, edited by Jonathan Rutherford, London: Lawrence and Wishart, 1990, pp. 207221.

${ }^{61}$ Stuart Hall, Stuart, “Cultural Identity and Diaspora”, In Identity: Community, Culture, Difference, edited by Jonathan Rutherford, London: Lawrence and Wishart, 1990, pp. 222-237.

Hall's conception of cultural identity parallels that of Bhabha's in its insistence on the non-essential and constructed nature of all identity. However, Hall is also careful to note the crucial and strategic value of deploying identity even as one is aware of its constructed nature - a political consciousness that is sometimes lacking in Bhabha's theorising. Hall's writing emerges from the Caribbean context, and in that sense is far removed from the cultural and colonial experiences of Sri Lanka, but it is still applicable to the Sri Lankan context in its dual trajectory of resisting essentialism coupled with the simultaneous recognition of the political value of invoking cultural identity. 